\title{
Aspectos Gerais de Cultivo, Métodos de \\ Secagem e Características da Cianobacteria Spirulina Platensis
}

\author{
Ulliana M. Sampaio, Karolline F. Siqueira, Christiane A. Starling \& \\ Flávia I. R. O. Araújo
}

O aumento da população mundial estimula diversas pesquisas na busca de fontes alternativas de alimentos, como as microalgas, devido ao seu potencial nutricional e diversificação de uso. A microalga mais estudada para fins alimentícios é a Spirulina platensis. O cultivo e comercialização da biomassa de Spirulina em alimentos são realizados em países como Estados Unidos, França, Índia, África e Tailândia. No Brasil, sua comercialização ocorre principalmente em cápsulas, comprimidos ou em pó. Realizou-se esta revisão bibliográfica, por meio de coleta de dados em Periódicos sobre a microalga Spirulina platensis, como o seu cultivo, processamento, utilização e aplicação no setor alimentício.

Palavras-chaves: microalga; cultivo; processamento.

The increase in world population stimulates several studies in the search for alternative food sources such as microalgae due to its nutritional potential and diversification of use. The microalgae studied further for food purposes is the Spirulina platensis. The cultivation and sale of Spirulina biomass in food are carried out in countries like USA, France, India, Africa and Thailand. In Brazil, marketing occurs mainly in capsule, tablet or powder. Held this literature review through data collection in Periodicals on Spirulina platensis, as its cultivation, processing, use and application in the food industry.

Keywords: microalgae; cultivation; processing. 


\section{Introdução}

A utilização de microalgas como alimento humano já é realizada há muitos anos em diversos países, como China, Índia, México, Peru, Japão e outros ${ }^{7,41}$.

A espécie Arthrospira platensis, conhecida também como Spirulina, é uma cianobactéria de origem africana ${ }^{41}$ com a capacidade de sintetizar compostos químicos usando dióxido de carbono e energia solar, e liberando oxigênio ${ }^{53}$. Desenvolve-se bem em temperaturas entre 25 a $30^{\circ} \mathrm{C}, \mathrm{pH}$ alcalino entre 9,5 e 11, e com concentrações elevadas de sal ${ }^{41}$.

A Spirulina apresenta um alto valor nutricional de proteínas, vitaminas, como a $\mathrm{B}_{12}$, sais minerais e pigmentos, tornando-se, dessa forma, uma matéria-prima de grande interesse para a indústria de alimentos, farmacêutica e cosmética. Estudos ainda demonstram as propriedades benéficas desta microalga na prevenção de doenças, melhoramento do sistema imunológico e ação antioxidante 53. Para que esses micro-organismos possam ser utilizados na alimentação humana, é necessário que haja uma concentração adequada de nutrientes, ausência de substâncias tóxicas e/ou alérgicas, e proporcionar aceitação sensorial ${ }^{57}$.

Os alimentos funcionais são a mais nova demanda do mercado, e a Spirulina tem sido empregada para o enriquecimento proteico e a elaboração de novos produtos, aliando a essa aplicação, a incorporação de tecnologias, adequação de padrões e restrições legais ${ }^{57}$. O sucesso de um novo produto depende da capacidade da empresa em traduzir os benefícios esperados do alimento para um determinado segmento de consumidores, definindo as características ideais do produto. Uma das estratégias para se agregar valor aos produtos alimentícios está justamente no uso de novos ou diferentes formas de aplicação de ingrendientes, embalagens e processos produtivos ${ }^{51}$.

Em países como França, Estados Unidos, China e Tailândia, há um rápido desenvolvimento no emprego da microalga em massas, pães, iogurtes e bebidas ${ }^{49 ; 2}$. No Brasil, a Spirulina é comercializada na maior parte em forma de comprimidos, cápsulas e em pó como suplementos alimentares para o público que pratica esportes regularmente e pessoas que buscam hábito saudável de vida ${ }^{47}$. Para ampliar o segmento no mercado brasileiro, pesquisas estão sendo realizadas para a uso dessa microalga em diferentes matrizes alimentares.

\section{Spirulina}

Pertencente à ordem Oscillatoriales, o gênero Spirulina é uma cianobactéria verde-azulada microscópica, fotossintética, unicelular, filamentosa, composta por tricomas de 5-6 $\mu \mathrm{m}$ de largura e 20-200 $\mu \mathrm{m}$ de comprimento em forma de um espiral, que tem seu habitat em águas alcalinas ${ }^{25 ; 61}$, sendo as espécies mais importantes são $S$. platensis, $S$. máxima e $S$. fusiformes. A reprodução da Spirulina ocorre por fissão transversal binária, em que há a formação do hormogônio (que gera um novo tricoma) que origina um novo filamento. Sua célula possui uma membrana plasmática cercada por multicamadas da parede celular, gram-negativas, apresentando uma fileira de poros ao redor do tricoma, separados por septos que são visíveis por microscopia óptica ${ }^{60}$.

A parede celular é cercada por uma cápsula composta por polissacarídeos e não apresenta celulose, tornado assim, a Spirulina, uma microalga de fácil assimilação pelos demais organismos, chegando a atingir uma porcentagem entre 85 e $95 \%{ }^{4}$.

Desde 23 de junho de 1981, a Spirulina foi legalmente aprovada pela FDA (Food and Drug Administration), como sendo uma fonte proteica, contendo várias vitaminas, com destaque para a provitamina A (betacaroteno) e minerais, como o ferro, além de compostos fenólicos, ficocianina, um corante natural, ácido gama-linolênico e outros ácidos graxos essenciais ${ }^{5 ; 41 ; 59}$.

Estudos nutricionais mostram que essa cianobactéria tem um dos mais altos teores de proteínas já encontrados, podendo atingir entre 60 e $70 \%$ de proteínas do seu peso seco, com uma digestibilidade proteica de $70 \%{ }^{5}$, 24 , e todos os aminoácidos essenciais (isoleucina, a leucina, a lisina, a metionina, a fenilalanina, a treonina e a valina) nas proporções recomendadas pela FDA, com exceção de metionina ${ }^{11}$.

O consumo diário de Spirulina que seria indicado para suprir as necessidades quanto aos aminoácidos essenciais para um adulto corresponderia a um valor de $25 \mathrm{~g} / \mathrm{dia}^{5,24}$. No entanto, esta quantidade é inviável para o consumo em cápsulas ou para a adição em produtos alimentícios, já que a Spirulina quando seca apresenta odor de peixe seco, e em pequenas proporções, causa alterações perceptíveis na palatabilidade e realce da 
cor verde ${ }^{8}$. Dessa forma, deve-se considerar também a ingestão de outras fontes de alimentos para se adquirir aminoácidos ${ }^{1}$.

\section{COMPOSIÇÃO DA SPIRULINA}

A composição química da Sprulina platensis é dependente da forma e otimização do seu cultivo, o que a torna variável, de acordo com os objetivos da sua produção. Seu conteúdo de proteínas é superior aos demais alimentos, apresentando uma média de $65 \%$, enquanto que na carne e no peixe a média é de $15-20 \%$, soja, $35 \%$, leite em pó, 35\%, amendoins, $25 \%$, ovos, $12 \%$, e grãos, $8-14 \%$. A composição média dos principais aminoácidos, ácidos graxos, minerais e vitaminas encontrados na microalga $S$. platensis estão descritos nas Tabelas 1, 2, 3 e 4 . Cerca de $1 \%$ do peso da Spirulina é representado pelo ácido $\gamma$-linolênico, que por ser de fácil extração, torna essa microalga fonte de ácidos graxos poli-insaturados e ácido ômega-3 viáveis ${ }^{12}$.

Os compostos fenólicos presentes na Spirulina spp são clorogênico, salicílico, sináptico e trans-cinâmico, que atuam como compostos antioxidantes em sistemas "in vivo" e "in vitro" ${ }^{39 ; 17}$. Quantos aos pigmentos presentes têm-se cerca de $20 \%$ do peso seco de ficocianina e $0,37 \%$ do peso seco de carotenoides ${ }^{52 ; 24}$.

\section{LEGISLAÇÃO}

A Spirulina está legalmente autorizada como alimento ou complemento alimentar na Europa, Japão e costa asiática do Pacífico. Já nos Estados Unidos, em 1981, a FDA determinou que, por ser uma boa fonte de nutrientes, pode ser comercializada legalmente como complemento alimentício ${ }^{24}$.

No Brasil, a Agência Nacional de Vigilância Sanitária (ANVISA) permite a comercialização, desde que o produto final esteja devidamente registrado, e respeitando a ingestão diária de 1,6 g/dia/indivíduo. A Spirulina tem sido empregada basicamente para a produção de cápsulas destinadas ao emagrecimento, embora sua aplicação seja ampla.

\section{PROPRIEDADES ANTINUTRICIONAIS}

Algumas espécies de cianobactérias são tóxicas, entretanto, até o momento, diversos artigos não documentaram nenhuma toxidade da Spirulina. Uma pesquisa realizada por Salazar et al (1998) com ratos alimentados por dieta enriquecida com Spirulina a níveis de 10 a $30 \%$, afirmaram não haver toxicidade crônica ou subcrônica, mutagênicidade ou teratogênicidade e nenhum efeito adverso na reprodução ou lactação, nem alergias dermatológicas nos ratos ${ }^{3}$.

No desenvolvimento de uma farinha desengordura com S. máxima, analisados alguns fatores antinutricionais, em que encontraram-se baixos índices de taninos, devido à presença de antocianina, e ausência das atividades hemaglutinante (lectina, proteína ou glicoproteína não imune), e inibidores de tripsina (inibidores de proteases). Entretanto, deve-se estar atento ao cultivo, pois pode ocorrer toxicidade por possíveis contaminações com outras microalgas tóxicas ${ }^{43}$.

\section{Métodos de Cultivo}

$\mathrm{O}$ cultivo de microalgas sofre variações em seu crescimento, conforme o sistema de cultivo utilizado e as condições do meio externo. As variáveis independentes do processo, como disponibilidade de nutrientes, temperatura, iluminação e modelo do fotobiorreator, podem ser controladas, a fim de estimular a biossíntese de determinados compostos, aumento da produtividade e redução de custos $^{22}$. As vantagens e desvantagens dos métodos de cultivos de forma geral estão expostas na Tabela 5.

\section{CULTIVO ABERTO}

A maior parte do cultivo das microalgas é realizado em lagos e tanques abertos que usufruem da luz solar e dióxido de carbono da atmosfera. Os tanques com esta configuração apresentam baixos custos de construção, sendo vantajoso financeiramente para os produtores, mas se deve levar em consideração a espécie a ser cultivada ${ }^{36}$. Os tanques podem ter variedade de formas e tamanhos, sendo o mais comumente utilizado o raceway ${ }^{19}$.

$\mathrm{Na}$ construção de tanques abertos, pode-se empregar uma ampla gama de materiais, variando de areia simples ou barro, a tijolos ou cimento, ou cloreto de polivinilo, fibra de vidro ou poliuretano, não sendo necessário nenhum material transparente. Estes apresentam também fácil manutenção de limpeza ${ }^{14 ; 52}$. 


\section{Artigo Geral 10}

Tabela 1. Composição de aminoácidos da Spirulina platensis em base seca.

\begin{tabular}{|c|c|c|c|c|c|}
\hline Aminoácido & Abreviação & $\%$ & Aminoácido & Abreviação & $\%$ \\
\hline Isoleucina* & Ile & 6,7 & Arginina & Arg & 7,3 \\
\hline Leucina* & Leu & 9,8 & Cisteína & Cys & 0,9 \\
\hline Lisina* & Lys & 4,8 & Tirosina & Tyr & 5,3 \\
\hline Metionina* & Met & 2,5 & Alanina & Ala & 9,5 \\
\hline Fenilalanina* & Phe & 5,3 & Ácido aspártico & Asp & 11,8 \\
\hline Treonina* & Thr & 6,2 & Ácido glutâmico & Glu & 10,3 \\
\hline Triptofano* & Trp & 0,3 & Glicina & Gly & 5,7 \\
\hline Valina* & Val & 7,1 & Prolina & Pro & 0,2 \\
\hline Histidina* & His & 2,2 & Serina & Ser & 5,1 \\
\hline Asparagina & Asn & ND & Glutamina & Gln & ND \\
\hline
\end{tabular}

*Aminoácidos essenciais. ND - Não determinado. Fonte: Richmond (2004).

Tabela 2. Percentual de ácidos graxos presentes em S. platensis em base seca.

\begin{tabular}{|c|c|c|c|c|c|}
\hline Ácidos graxos & Abreviação & $\%$ & Ácidos graxos & Abreviação & Ácido esteárico \\
\hline Ácido láurico & $12: 0$ & 0,4 & Ácido oléico & $18: 0$ & $18: 1$ \\
\hline Ácido mirístico & $14: 0$ & 0,7 & Ácido linoléico & $18: 2$ & 3,8 \\
\hline Ácido miristoleico & $14: 1$ & 0,2 & Ácido $\alpha$-linolênico & $18: 3$ & 14,5 \\
\hline Ácido palmítico & $16: 0$ & 45,5 & Ácido $\gamma$-linolênico & $18: 3$ & $20: 2$ \\
\hline Ácido palmitoleico & $16: 1$ & 9,5 & Ácido eicosadienóico & ND \\
\hline $\begin{array}{c}\text { Ácido } \\
\text { hexadecadienoico }\end{array}$ & $16: 2$ & 1,2 & Ácido eicosatrienóico & $20: 3$ \\
\hline $\begin{array}{c}\text { Ácido } \\
\text { heptadecanoico }\end{array}$ & $17: 0$ & 0,3 & 0,4 \\
\hline
\end{tabular}

Fonte: Richmond (2004).

Tabela 3. Vitaminas identificadas na biomassa seca de S. platensis, no leite de vaca em pó, soja e no ovo de galinha.

\begin{tabular}{|c|c|c|c|c|c|}
\hline Vitaminas & Abreviação & $\begin{array}{l}\text { S. platensis } \\
(\mathrm{mg} / 100 \mathrm{~g})\end{array}$ & $\begin{array}{l}\text { Leite de vaca em pó } \\
\qquad(\mathrm{mg} / 100 \mathrm{~g})\end{array}$ & Soja $(\mathrm{mg} / 100 \mathrm{~g})$ & $\begin{array}{l}\text { Ovos de galinha } \\
\quad(\mathrm{mg} / 100 \mathrm{~g})\end{array}$ \\
\hline Ácido ascórbico & $\mathrm{C}$ & $42,0-195,3$ & 6 & $\operatorname{Tr}$ & 0 \\
\hline Calciferol & $\mathrm{D}$ & $12000 \mathrm{U}$ & ND & ND & ND \\
\hline Tocoferol & $\mathrm{E}$ & $10-19$ & ND & ND & ND \\
\hline Tiamina & B1 & $0,8-15,4$ & 0,29 & 0,66 & 0,1 \\
\hline Riboflavina & $\mathrm{B} 2$ & $0,2-0,9$ & 1,03 & 0,04 & 0,58 \\
\hline Nicotinamida & B3 & $0,6-5,3$ & 0,7 & 2,2 & 0,1 \\
\hline Piroxidina & B6 & $0,3-4,0$ & $\operatorname{Tr}$ & 0,03 & $\operatorname{Tr}$ \\
\hline Cianocobalamina & B12 & $0,3-0,8$ & ND & ND & ND \\
\hline
\end{tabular}

Tr - Traços. ND - Não determinado - Fonte: Richmond (2004). 
Tabela 4. Minerais identificados na biomassa seca de S. platensis, no leite de vaca em pó, soja e no ovo de galinha.

\begin{tabular}{|c|c|c|c|c|c|}
\hline Minerais & Abreviação & $\begin{array}{c}\text { S. platensis } \\
(\mathrm{mg} / 100 \mathrm{~g})\end{array}$ & $\begin{array}{c}\text { Leite de vaca em pó } \\
(\mathrm{mg} / 100 \mathrm{~g})\end{array}$ & $\begin{array}{c}\text { Soja (mg/100g) de galinha } \\
(\mathrm{mg} / 100 \mathrm{~g})\end{array}$ \\
\hline Cálcio & $\mathrm{Ca}$ & 4.000 & 890 & 206 \\
\hline Ferro & $\mathrm{Fe}$ & 1.060 & 0,5 & 13,1 & 1.922 \\
\hline Potássio & $\mathrm{K}$ & 15.200 & 1.132 & 242 & 150 \\
\hline Magnésio & $\mathrm{Mg}$ & 4.800 & 77 & 2,87 & 13 \\
\hline Manganês & $\mathrm{Mn}$ & 26 & $\mathrm{Tr}$ & $\mathrm{ND}$ & $\mathrm{Tr}$ \\
\hline Molibdênio & $\mathrm{Mb}$ & 1,5 & $\mathrm{ND}$ & $\mathrm{ND}$ \\
\hline
\end{tabular}

Tr - Traços. ND - Não determinado - Fonte: Richmond (2004).

Tabela 5. Vantagens e desvantagens dos sistemas de cultivo aberto e fechado de microalgas.

\begin{tabular}{|c|c|c|}
\hline Parâmetros & Tanques (raceways) & Sistemas fechados (fotobiorreatores) \\
\hline Espaço requerido & Muito & Pouco \\
\hline Risco de contaminação & Alto & Médio a baixo \\
\hline Perdas de água & Alto & Baixo \\
\hline Concentração de oxigênio & Usualmente baixa & Deve ser removido continuamente \\
\hline $\mathrm{CO} 2$ perdas & Alto & Muito baixo \\
\hline Reprodutibilidade da produção & Variável, mas consistente & Possível dentro de determinadas tolerâncias \\
\hline Controle do processo & Limitado & Possível \\
\hline Desgaste do material de construção & Baixo & Usualmente alto \\
\hline Dependência de condições climáticas & Alto & Menor, por ser protegido \\
\hline Temperatura & Variável & Necessário resfriamento \\
\hline Custo de colheita & Alto & Médio \\
\hline Manutenção & Fácil & Difícil \\
\hline Custos de construção & Médio & Alto \\
\hline Concentrações de biomassa na colheita & Baixo $(0,1-0,5 \mathrm{~g} / \mathrm{L})$ & Alto $(2-8 \mathrm{~g} / \mathrm{L})$ \\
\hline Variedade de espécies cultivadas & Pouca & Alta, quase todas as espécies \\
\hline Flexibilidade de produção & Nenhuma & Alta \\
\hline Padronização & Nenhuma & Possível \\
\hline $\begin{array}{l}\text { Período até produção líquida ser alcançada } \\
\text { após o início ou interrupções }\end{array}$ & Longo & Curto \\
\hline Eficiência dos processos downstream & $\begin{array}{l}\text { Baixa, grande volume com baixas } \\
\text { concentrações }\end{array}$ & Alta, volumes menores altas concentrações \\
\hline
\end{tabular}


As principais plantas utilizam membranas plásticas de longa duração para o revestimento interno, como PVC resistente a raios UV. Alguns sistemas visando à redução de custos, não usam material de revestimento, o que pode levar à suspensão de sedimentos, percolação e alta probabilidade de contaminação de cultura. Além disso, seu uso é restrito a determinados tipos de solo e condições ambientais ${ }^{52}$.

Um dos principais parâmetros no design de construção é a questão de se obter uma baixa profundidade do tanque, de até $30 \mathrm{~cm}$, para garantir que a luz incida sobre as células $^{10}$. Dessa forma, a produtividade será maximizada em uma concentração ótima de biomassa determinada por unidade de área. Nestas condições, com o volume reduzido e a concentração de biomassa maximizada, aspectos operacionais, como manejo de recursos hídricos, recuperação de biomassa, podem ser mais práticos e econômicos. Entretanto, há grandes perdas de dióxido de carbono para atmosfera, alta variação de temperatura e evaporação. Outro parâmetro relevante é o tamanho da área superficial, sendo necessário possuir grandes áreas superficiais para aumentar o aproveitamento da luz'.

Inicialmente, é realizado a inoculação da microalga, entre 5 a 7 dias dependendo do tamanho do inóculo, temperatura e iluminação, em que há o crescimento exponencial. Após a obtenção da fase exponencial, coleta-se a cultura e esta é transferida para os tanques. A operação é contínua, e os tanques recebem constantemente $\mathrm{CO}_{2}$ e os nutrientes, e do lado oposto parte da água com microalgas é removida. As microalgas e nutrientes circulam constantemente com auxílio da agitação produzida por meio de rodas de pás, para garantir a mistura, homogeneidade, suspensão, oxigenação e evitar a fotoinibição ${ }^{10}$.

Outra forma de apresenstação do sistema aberto é cobrí-lo com uma superfície, como se fosse uma estufa para reduzir as desvantagens do sistema totalmente aberto e aumentar a produtividade. Mas, de qualquer forma, haverá uma maior produção nos sistemas fechados ${ }^{61}$, quando se refere a produtividade volumétrica ${ }^{36}$.

\section{CULTIVO FECHADO}

O cultivo fechado geralmente é utilizado para produção em larga escala, apresentando a vantagem de obter uma maior concentração de biomassa e maior controle dos parâmetros de cultivo, reduzindo as perdas de dióxido de carbono, evaporação e os riscos de contaminação devido ao menor contato com o meio externo".

No cultivo fechado, há o uso de fotobiorreatores que podem ser são classificados em tubulares, colunas e planares, constituídos de material transparente, para promover a melhor distribuição de luz ${ }^{13}$. Entretanto, os custos de implementação e de operação destes sistemas são os mais caros, apresentando também dificuldades como superaquecimento, entupimento e outros ${ }^{9}$.

O fotobiorreator de coluna possui uma superfície de captação de luz solar e pode ser dividido em duas unidades: a coluna, onde se encontra o meio de cultura e ocorre à captação de luz para a fotossíntese; e uma unidade geradora de bolhas, com função de misturar o meio de cultura e realizar a transferência de gases ${ }^{16}$.

O fotobiorreator tubular foi desenvolvido na década de 1950, sendo composto normalmente por material transparente como PET, acrílico e vidro, com diâmetro de até $10 \mathrm{~cm}$, para auxiliar na incidência da luz sobre a cultura. O tamanho dos tubos também é limitado, pois apresenta baixa capcidade de retenção de oxigênio. Esse fotobiorretador pode ser disposto na horizontal, na vertical ou em espiral ${ }^{52 ; 26}$.

Assim, como os outros fotobiorreatores, o de placas também possui uma superficie de captação de luz, mas esta é superior, favorecendo uma maior produção. Além disso, também acumulam uma baixa taxa de oxigênio e possui uma maior eficiência no processo de fotossíntese ${ }^{10}$.

\section{Meios de Cultivo}

Para o desenvolvimento e produtividade das microalgas, é essencial o conhecimento dos nutrientes necessários para o cultivo. Devido à variação na quantidade e tipos de nutrientes, o meio de cultivo pode se adequar aos diferentes grupos de microalgas. Estudaramse diversos elementos químicos para definir suas importâncias na cinética de crescimento das microalgas. Mas, como certos elementos são essenciais para algumas espécies e para outros não, ainda não foi consolidado um número universal desses elementos. Reconhecemse cerca de 15 a 21 elementos considerados como essenciais, que foram divididos entre macronutrientes e micronutrientes ${ }^{33 ; 55}$.

A Spirulina tem capacidade de crescer em ambiente autótrofico, mixotrófico e heterotrófico ${ }^{40}$, sendo que a diferença desses meios está na fonte de energia e 
carbono $^{17,45}$. O meio padrão para cultivo de Spirulina foi desenvolvido por Zarrouk (1996), o qual fornece carbono inorgânico na forma de $\mathrm{CO}_{3}{ }^{2-}$ e $\mathrm{HCO}^{3-}$, que se convertem em $\mathrm{CO}_{2}$ utilizado na fotossíntese. Entretanto, como a fonte de carbono é um dos maiores componentes de custos, a diluição do meio Zarrouk (padrão para o cultivo da microalga Spirulina) torna-se uma alternativa a ser estudada, já que a alta concentração de sais do meio aumenta os custos de produção ${ }^{29}$.

A Spirulina apresenta baixa susceptibilidade à contaminação de seus cultivos por outros microorganismos devido ao seu alto $\mathrm{pH}$, de modo que seus biorreatores podem ser abertos, sendo geralmente de forma retangular com cantos arredondados ${ }^{59}$.

Existe uma quantidade bem menor de dados sobre cultivos heterotróficos e mixotróficos do que sobre os cultivos autotróficos, uma vez que nesses cultivos são utilizados fontes de carbono orgânico. Todavia, os cultivos heterotrófico e mixótrófico apresentam a vantagem de aumentar a produtividade em biomassa e em lipídeo, observando que no modo heterotrófico somente algumas microalgas são capazes de crescerem sem que seja feita alguma manipulação genética ${ }^{32}$.

\section{AUTOTRÓFICO}

No cultivo autotrófico, as células obtêm energia da luz e carbono do $\mathrm{CO}_{2}$ do ar o $\mathrm{HCO}^{3-}$ dissolvido na água ${ }^{2}$, produzindo, através da fotossíntese, seus polissacarídeos, proteínas, lipídeos e ácidos nucleicos ${ }^{28}$. Apesar da alta eficiência no uso da luz, o crescimento das microalgas é lento em grandes escalas, causado pela alta densidade de células devido à quantidade excessiva de luz ${ }^{50}$. Nesse tipo de cultivo, um aspecto positivo é a possibilidade de uso do dióxido de carbono resultante de processos industriais, favorecendo uma redução dos custos de produção da biomassa ${ }^{27}$.

Além da luz e do carbono, para haver crescimento autotrófico são necessários nutrientes como nitrato, fósforo, potássio e metais, vitaminas, e uso de temperatura e $\mathrm{pH}$ dentro das características de desenvolvimento da microalga cultivada ${ }^{2}$.

\section{HETERÓTROFO}

No cultivo heterotrófico, as células utilizam compostos orgânicos como fonte de energia e de carbono $^{28}$, não necessitando de luz, podendo, assim, aumentar a concentração celular e a produtividade de biomassa em larga escala ${ }^{20}$. Estudos ${ }^{38 ; 62 ; 31}$ demostraram também, que nesse tipo de cultivo há um aumento no teor de lipídeos em relação ao cultivo autotrófico, sendo uma vantagem para produção de biomassa destinada a geração de biodiesel. Como consequência, há uma redução nos teores de proteína, clorofila e carotenoides ${ }^{15}$, que poderia ser revertido no uso do cultivo mixotrófico, em que há o estímulo da luz. No entanto, em altas concentrações celulares a luz se torna limitante com taxa de crescimento global muito baixa, com consequente diminuição na produção de proteína e clorofila ${ }^{44}$.

\section{MIXOTRÓFICO}

No cultivo mixotrófico utiliza-se a luz, compostos orgânicos e inorgânicos como fonte de energia e dióxido de carbono, e compostos orgânicos como fonte de carbono, sendo esse cultivo uma alternativa para a produção fotoautotrófica ${ }^{28}$.

A combinação de fontes de carbono adversas com o meio Zarrouk pode possibilitar o cultivo da microalga com menores custos e maiores produtividades. A glicose adicionada a este meio, por exemplo, como fonte de carbono, demonstra redução na respiração aeróbia em altas intensidades de luz, com inibição da utilização de glicose pelas células e, em baixas intensidades de luz, a respiração torna-se prioritária, necessitando de maiores concentrações de glicose para atender a demanda do crescimento celular. Dessa forma, as concentrações celulares da microalga podem ser aumentadas pelo uso de glicose como fonte de carbono, desde que adicionada em baixas concentrações no meio de cultivo, demonstrando a capacidade metabólica dessa microalga de converter fontes orgânicas de carbono em biomassa ${ }^{43}$.

\section{Crescimento da Microalga}

\section{ILUMINÂNCIA}

A influência da luz está relacionada com o tempo de exposição, intensidade, cor e comprimento de onda que incide sobre a cultura, podendo afetar, por exemplo, o teor de proteínas e clorofila, e principalmente, a produção de biomassa por unidade de área num determinado tempo. 
Altas intensidades de luz pode causar foto-oxidação, que leva a perda da cultura, e a fotoinibição, que pode provocar a queda do rendimento. O limite de saturação de luz é aproximadamente de 5-10 Klux por cianobactéria ${ }^{42}$.

A S. platensis é mais sensível à fotoinibição quando está acondicionada sob temperatura abaixo da ótima de crescimento. Assim, nos cultivos abertos, a combinação de temperaturas relativamente baixas no período da manhã, com a rápida elevação da incidência luminosa, pode favorecer esse fenômeno, levando as cianobactérias a promover um autosombreamento com a compressão dos tricomas ${ }^{34}$.

\section{TEMPERATURA}

A temperatura influencia nas reações metabólicas, taxa de crescimento $^{36}$ e consequentemente na composição química, podendo aumentar ou reduzir a concentração de alguns compostos. Em clima temperado, utilizase temperaturas entre 10 e $25^{\circ} \mathrm{C}$ e acima de $20^{\circ} \mathrm{C}$ para regiões com clima tropical. No geral, têm-se que abaixo de $16^{\circ} \mathrm{C}$ pode haver a redução da taxa de crescimento e superior a $35^{\circ} \mathrm{C}$ pode ser fatal a espécie cultivada ${ }^{23}$.

\section{PH}

O controle do $\mathrm{pH}$, geralmente, na faixa de 7 a 9, é importante para que os componentes do meio de cultura possam ser absorvidos e, assim, disponibilizar os elementos químicos ${ }^{34}$. A $S$. platensis é alcalófila obrigatória, o que dificulta a sobrevivência de outros organismos ${ }^{6}$ e acaba por fornecer certa segurança à qualidade do cultivo aberto. A variação de biomassa em relação ao $\mathrm{pH}$ se deve à sua influência na disponibilidade de nutrientes, na atividade de estruturas celulares e de suas enzimas. Um $\mathrm{pH}$ superior a 10 pode levar a uma redução na produtividade ${ }^{52}$, ou mesmo em colapso completo, se houver falha na manutenção de $\mathrm{pH}^{23}$. Para se regular o $\mathrm{pH}$ e estimular o crescimento, adiciona-se dióxido de carbono ou tampões como o Tris (2-amino-2-[hidroximetil]-1-3-propanediol) e a glicilglicina ${ }^{34}$.

\section{AGITAÇÃO}

O grau de agitação é importante para evitar declínio na produtividade, rompimento de tricomas e eliminar o oxigênio supersaturado, sendo necessário, portanto, estudar qual a agitação ideal para os cultivos ${ }^{52}$. As microalgas crescem naturalmente em regimes não turbulentos e, dessa forma, nem sempre, irão se adaptar a agitações vigorosas. Normalmente, realiza-se essa operação por borbulhamento com ar, com pás circulares ou por bombeamento. Entretanto, a agitação turbulenta pode ser vantajosa em sistemas fechados, devido à melhoria de circulação interna e o não depósito de células em zonas escuras ${ }^{16 ; 23}$.

\section{NUTRIENTES}

Os macronutrientes têm diversas funções, como serem fontes dos constituintes estruturais das biomoléculas e regular atividades metabólicas. Já os micronutrientes, como o ferro e o manganês, participam da estrutura e da atividade de enzimas que são envolvidas nas diversas vias metabólicas ${ }^{34}$.

O carbono é necessário em altas concentrações por ser constituinte de todas as substâncias orgânicas sintetizadas pelas células (proteínas, carboidratos, ácidos nucleicos, vitaminas, lipídeos, e outros). A $S$. platensis permite a combinação entre a fotossíntese e a assimilação heterotrófica de compostos orgânicos, num processo chamado mixotrofia. Esse processo permite a utilização de outros nutrientes como fonte de carbono. O bicarbonato é o mais empregado em meios de cultura. Ele é incorporado e convertido em $\mathrm{CO}_{2}$, que é destinado à fotossíntese e, em carbonato, que é liberado para o meio extracelular, aumentando o $\mathrm{pH}$ do cultivo ${ }^{34}$.

O dióxido de carbono é a uma fonte de carbono que pode ser utilizado diretamente na fotossíntese ${ }^{14}$. Outra fonte de carbono é o acetato, que vem demostrando o aumento da biomassa e o conteúdo de carotenos, provavelmente, devido ao ácido acético ser um precursor dos carotenoides. Além do carbono, o nitrogênio também é fundamental para o crescimento das cianobactérias. Ele faz arte da estrutura de proteínas, ácidos nucleicos e pigmentos fotossintetizantes (clorofila e ficobilina). Em altas concentrações ,em um aumento na concentração de proteínas e clorofila, e em baixas concentrações, há a redução no teor de proteínas e na taxa de divisão celular. A concentração de ácido linolênico aumenta, os ácidos graxos permanecem constantes, as ficocianinas são degradadas e utilizadas como fonte de nitrogênio. Formam-se mais carotenoides e menos clorofilas, 
gerando mudanças de cor que tendem ao amarelado ${ }^{34}$.

A ureia também é estudada para reduzir os custos de produção. Entretanto, sua hidrólise em amônia sob condições alcalinas gera perdas de nutrientes por volatilização e redução da produção devido ao efeito tóxico deste composto ${ }^{34}$.

\section{Coleta da Biomassa}

Não existe um método padrão para a coleta e separação de biomassa, podendo ser realizado a separação da microalga da água por centrifugação, ou por floculação, que tem uma menor demanda energética, e flotação como métodos coadjuvantes. A escolha do método é baseada nas características da microalga, cultivada e no custo, já que, geralmente, este representa cerca de 20 a 30\% do total da produção da biomassa. No caso da Spirulina spp., as células são relativamente grandes e é fácil separar a biomassa da água por filtração ${ }^{19}$.

A centrifugação é um método aplicado com sucesso por ser bastante eficiente. Entretanto, o processo envolve a exposição das células a elevadas forças gravitacionais e de cisalhamento, que podem danificar a estrutura da célula. Também apresenta altos custos e alta demanda de energia. A filtração, microfiltração, eletrocoagulação e biofloculação vêm sendo estudados como processos alternativos $^{29 ; 46 ; 48 ; 52 ; 54}$.

\section{Métodos de Secagem}

A secagem tem como objetivo a remoção de líquido de um material, que será seco pelo contato com ar insaturado, resultando na redução da umidade do material e do ar. É uma operação operação bastante difundida, conferindo estabilidade físico-química e microbiológica ao produto, prorrogando a vida de prateleira. Para o processo de secagem, dois estágios podem ser definidos: aquecimento do material e evaporação da sua umidade ${ }^{42}$.

$\mathrm{Na}$ secagem de microalgas, têm sido empregados métodos como o spray dryer, secador de cabine, liofilizadores e secagem ao sol. Independente do processo escolhido, o processo deve manter critérios de qualidade, como a cor, nutrientes, forma ou textura, e por isso, a liofilização pode ser considerada método de referência para cianobactérias, já que não há alterações nas propriedades nutricionais, sensoriais e físico-químicas, além de se assemelhar com a biomassa fresca ${ }^{42}$. Esse processo rompe as células da biomassa de microalgas, transformando-as em um pó solto, fazendo com que nenhum outro tratamento seja necessário. As únicas desvantagens desse processo são o custo elevado e a necessidade de mão-de-obra especializada ${ }^{36}$.

A secagem ao sol é um dos métodos mais atrativos, devido ao seu baixo custo de implantação. Ela é recomendável em regiões de clima seco, com boa irradiação solar e baixo índice de precipitação pluviométrica. Essa secagem não é onerosa e não necessita de mão-de-obra qualificada. Entretanto, demanda longos períodos de secagem, há maiores riscos de contaminação, necessidade de grandes áreas, controle rigoroso de insetos e roedores e apresenta risco de perda de material. A biomassa deve ficar disposta em tabuleiros ou lonas, previamente higienizados, sobre armações, sobre piso de cimento ou pedregulho, que irradiam melhor o calor ${ }^{56 ; 21}$.

Os secadores de bandeja são usados em pequenas escalas (1 a 20 t/dia) ou escala piloto. Os custos são baixos, mas não possui um alto controle sobre as condições de secagem, resultando em produtos com qualidade variável se não houver uma distribuição homogênea do ar. O secador de bandeja possui um isolamento externo, e as bandejas onde será colocado o material a ser desidratado são perfuradas. Nesse tipo de secagem o ar é impulsionado por um ventilador que passa por um sistema de aquecimento. $\mathrm{O}$ ar aquecido entra em contato com as bandejas permanecendo pelo tempo necessário da operação ${ }^{18}$.

O método por spray dryer transforma líquidos em produtos secos e pulverizados, através de um sistema centrífugo ou de alta pressão, em que as gotículas atomizadas entram em contato com um fluxo de ar quente. A rápida evaporação permite manter baixa a temperatura do produto. A transferência de calor e de massa é realizada pelo contato direto entre o gás quente e as gotículas dispersas. As partículas finas são separadas do gás em ciclones externos ou em mangas coletoras ${ }^{37}$; 35; 33; 58 . A vantagem desse processo é a formação de partículas esféricas e homogêneas, facilitando o processo de manuseio e envase, com redução de $\operatorname{custos}^{30}$.

\section{Conclusão}

A cianobactéria Spirulina é uma das microalgas 
mais estudadas para o consumo humano, devido a sua composição química, e pela sua facilidade de digestão, por não apresentar celulose em sua parede celular como outras microalgas eucarióticas. A cinética de crescimento de micro-organismos é algo complexo, com diversas variavéis a serem consideradas, principalmente, em relação ao $\mathrm{pH}$, luz e nutrientes. Esses parâmetros devem ser mantidos para que não haja perdas da cultura ou redução da produção. Entretanto, apesar da dificuldade de controle do processo, o seu cultivo em sistemas abertos responde bem a produtividade por área, além de não ter altos custos de implantação, e ser mais viavél para pequenos produtores.

\section{Referências}

1. Andersen, R. A. Algal culturing techniques. Elsevier Academic Press: China, 2005.

2. Andrade, M. R.; Costa, J. A. V. Ciência e Agrotecnologia, 2008, 32,1551 .

3. Babadzhanov, A. S. et al. Chemistry of Natural Compounds, 2004, 40, 276.

4. Belay, A.; Yoshimichi, O. Journal of Appl. Phycology, 1993, 5, 235.

5. Belkin, S.; Boussiba, S. Plant Cell Physiol., 1991, 32, 953.

6. Bertoldi, F. C.; Sant'anna, E.; Oliveira, J. L. B. Boletim do CEPPA, 2008, 26, 9.

7. Borja, F. Spirulina. Jornal Tamanduá. Patos, jan. 2007. Disponível em: $<$ www.fazendatamandua.com.br/jt-jan07.htm $>$. Acesso em: 05/04/2014.

8. Borowitzka, M. A.; Hallegraeff, G. M. Algae of Australia: introduction; McCarthy, P. M.; Orchard, A. E., eds.; Australian Biological Resources Study: Canberra, 2007, cap. 29.

9. Brennan, L.; P. Owend, E. Renewable and Sustainable Energy Reviews, 2010, 14, 557.

10. Colla, L. M. et al. Bioresource Technology, 2007, 98, 1489.

11. Cozza, K. L.; COSTA, J. A. V. Vetor, Revista de Ciências Exatas e Engenharias, 2000, 10, 69.

12. Demirbas, A. Energy Convers. Manage., 2010, 51, 2738.

13. Derner, R. B. et al. Ciência Rural, 2006, 36, 1959.

14. Endo, H. et al. Agricul. Biol. Chem., 1974, 38, 9.

15. Eriksen, N. Biotechnology Letters, 2008, 30, 1525.

16. Estrada, J. E.; Bescos, P.; Villar Del Fresno, A. M. Il Farmaco, 2001, 56, 497.

17. Fellows, P. J. Tecnologia de processamento dos alimentos. 2 ed. Porto Alegre: Artmed, 2006, 602 p.
18. Franco, et al. Quim. Nova, 2013, 36, 437.

19. García, M. C. et al. J. Appl. Phycol., 2000, 12, 239.

20. Gava, A. J. Princípios e tecnologia de alimentos. 2 ed. São Paulo: Nobel, 1998, 284 p.

21. Grobbelaar, J. J. Appl. Phycol., 2009, 21, 523.

22. Gualtieri, P.; Barsanti, L. Algae: anatomy, biochemistry, and biotechnology. CRC Press, Taylor e Francis Group. 301 p., 2006.

23. Henrikson, R. Microalga Spirulina superalimento del futuro. 1a Edição. Barcelona: Ediciones Urano, 1994, 222 p.

24. Hoff, F. H.; Snell, T. W. Plankton Culture Manual. 5 ed. Florida: Aqua Farms, 1999, 226 p.

25. Holanda, L. R. de et al. O cultivo de microalgas para a geração de eletricidade. In: VII Congresso Nacional de Excelência em Gestão. 2011.

26. Huang, G. et al. Appl. Energy, 2010, 87, 38.

27. Jiang, L. et al. Appl. Energy, 2011, 88, 3336.

28. Knuckey, R. M. et al. Aquacult. Eng., 2006, 35, 300.

29. Lannes, C. S. da S.; Medeiros, M. L. Brazilian Journal of Pharmaceutical Sciences, 2003, 39, 115.

30. LI, Y. et al. Appl. Energy., 2011, 88, 3313.

31. Liang, Y.; Sarkany, N.; CUI, Y. Biotechnol. Lett., 2009, 31, 1043.

32. Linoya, K.; Gotoh, K.; Higashitani, K. Powder technology handbook. New York: Wiley, 1991. 794 p.

33. Lourenço, S. O. Cultivo de microalgas marinhas: princípios e aplicações. São Carlos: RiMa, 2006. 606p.

34. Masters, K. Spray drying handbook. 4.ed. London: Godwin, 1985. $696 \mathrm{p}$.

35. Mata, T. M.; Martins, A. A.; Caetano, N. S. Renewable and Sustainable Energy Reviews., 2010, 14, 217.

36. Mccabe, W. L.; SMITH, J. C. Unit operations of chemical engineering . New York: McGraw-Hill, 1956. 945 p.

37. Miao, X.; WU, Q. Bioresour Technol., 2006, 97, 841.

38. Miranda, M. S. et al. Brazilian Journal of Medical and Biological Research, 1998, 31, 1075.

39. Moazami, N. et al. Biomass and Bioenergy, 2011, 35, 1935.

40. Moraes, I. de O. et al. Ciênc. Tecnol. Aliment., 2013, 33, 179.

41. Morist, A. et al. Process Biochemistry, 2011, 37, 535.

42. Muliterno, A. et al. Ciênc. agrotec., 2005, 29, 1132.

43. Ogawa, T.; AIBA, S. Biotechnol. Bioeng., 1981, 23, 1121.

44. Ogbonna, J. C.; Masui, H.; Tanaka, H. J. Appl. Phycol., 1997, 9, 359 .

45. OH, H. M. et al. Biotechnol. Lett., 2001, 23, 1229.

46. Perez, K. J. et al. Alim Nutr., 2007, 18, 77. 
47. Poelman, E.; DE PAUW, N.; JEURISSEN, B. Resour. Conserv. Recy., 1997, 19, 1.

48. Pulz, O.; GrosS, W. Applied Microbiological Biotechnology, 2004, 65, 635.

49. Ragni, M. et al. J. Phycol., 2008, 44, 670.

50. Rego, A. Ingredientes: novas funcionalidades. In: Brasil Food Trends 2020. São Paulo, 2010. Cap. 5.2, p.99-107.

51. Richmond, A. Handbook of Microalgal Mass Culture: Biotechnology and Applied Phycology. Blackwell Science, 2004.

52. Rojas, E.; Ávila, M.; Parada, G. Latin American Journal of Lat. Am. J. Aquat. Res., 2012, 40, 763.

53. Rossignol, N. et al. Aquacult. Eng., 1999, 20, 191.

54. Shimamatsu, H. Hydrobiologia, 2004, 512, 39.

55. Silva, J. A. Tópicos da tecnologia dos alimentos. São Paulo: Varela, 2000. 232 p.

56. Toledo, J. C. et al. Gestão \& Produção, 2008, 15, 117.

57. Van't land, C. M. Industrial drying equipment: Selection and application. New York: Marcel Dekker, 1991. 362 p.

58. Von der weid, d.; dillon, j. C.; falquet, J. Malnutrition: a silent massacre. Geneve: Antenna Technology, 2000.

59. Vonshak, a; tomaselli, I. Arthrospira (Spirulina): Systematics and ecophysiology. In: The Ecology of Cyanobacteria. Kluwer Academic Publishers. Dordrecht, Holanda, p. 505 - 522, 2000.

60. Wellinger, A. Algal biomass does it save world? Shot reflections IEA Bioenergy: An international collaboration in bioenergy, april, 2009.

61. Xu, H.; Miao, X.; Wu, Q.; j. Biotechnol., 2006, 126, 499

\section{Ulliana M. Sampaio', Karolline F. Siqueira, Christiane A. Starling \& Flávia I. R. O. Araújo ${ }^{\star 2}$}

\footnotetext{
${ }^{1}$ Universidade Estadual de Campinas, Cidade Universitária Zeferino Vaz - Barão Geraldo, Campinas, São Paulo, Brasil 13083-970

${ }^{2}$ Instituto SENAI de Tecnologia em Alimentos e Bebidas,- Rua Professor Lázaro Costa n 348, Vila Canaã, CEP: 74415-420 - Goiânia, Goiás, Brasil.
}

*E-mail: flaviaisaraujo.senai@sistemafieg.org.br 